\title{
Analisis Tingkat Kekumuhan Permukiman Pesisir Di Kecamatan Abeli
}

\author{
Sitti Asyfa ${ }^{1)}$, Irfan Ido $^{2)}$, Nurgiantoro ${ }^{2)}$ \\ 1) Jurusan Geografi Universitas Halu Oleo \\ ${ }^{2} J u r u s a n$ Geografi Universitas Halu Oleo
}

Email:sittiasyfa24@gmail.com

\begin{abstract}
Abstrak: Penelitian ini bertujuan untuk menentukan indeks kekumuhan permukiman pesisir dan menganalisis kondisi eksisting permukiman di Kecamatan Abeli Kota Kendari dengan menggunakan analisis deskriptif kuantitatif. Penelitian ini menggunakan metode overlay dengan memberikan penilaian pada setiap indikator kekumuhan yang telah ditetapkan oleh Dirjen Perumahan dan Permukiman seperti: kepadatan bangunan, kelayakan bangunan, aksesibilitas lingkungan, drainase lingkungan, pelayanan air bersih, pengelolaan air limbah dan pengelolaan persampahan. Hasil penelitian menunjukkan bahwa indeks kekumuhan permukiman pesisir di Kecamatan Abeli terdiri dari dua kelas yaitu kumuh sedang dan kumuh berat. Kelas kumuh sedang dengan indeks kekumuhan 2,53,4 terdapat di Kelurahan Pudai RT 02, Kelurahan Lapulu RT 01 dan 02, Kelurahan Poasia RT 03 dan 05, Kelurahan Talia RT 01. Kelas kumuh berat dengan indeks kekumuhan 3,5- 4,4 terdapat pada Kelurahan Pudai RT 01, Kelurahan Lapulu RT 03 dan Kelurahan Talia RT 02, 03 dan 04. kondisi eksisting untuk tingkat permukiman kumuh sedang memiliki kondisi lingkungan umumnya cenderung menengah, dimana terdapat beberapa aspek yang memiliki kesamaan dengan permukiman kumuh ringan. Kondisi kumuh berat kondidsi lingkungannya buruk, terdapat kecenderungan bahwa semakin buruk tingkat kekumuhan permukiman, maka semakin buruk pula kondisinya dengan memilki kondisi sarana dan prasarana yang tidak memadai dan kondisi lingkungan yang kurang terjaga.
\end{abstract}

Kata Kunci: permukiman kumuh, tingkat kekumuhan, overlay parameter

Abstract: This study aims to determine the slum index of coastal settlements and analyze the existing conditions of settlements in Kendari City Abeli District using quantitative descriptive analysis. This study uses the overlay method by giving an assessment of each slum indicator set by the Director General of Housing and Settlements such as: building density, building feasibility, environmental accessibility, environmental drainage, clean water services, waste water management and waste management. The results showed that the slum index of coastal settlements in Abeli Subdistrict consisted of two classes namely medium slums and heavy slums. Where moderate slum with 2.5-3.4 slum index found in Pudai Village RT 02, Lapulu Village RT 01 and 02, Poasia Village RT 03 and 05, Talia Village RT 01. For heavy slum classes with 3.5- slum index 4.4 is found in Pudai RT 01 Village, Lapulu Village RT 03 and Talia RT 02, 03 and 04 Village. With the existing conditions for slum settlements having moderate environmental conditions generally tend to be medium, where there are several aspects that have similarities with light slum settlements. While the condition of heavy slum conditions is poor, there is a tendency that the worse the slum level of settlements, the worse the condition is by having inadequate conditions of facilities and infrastructure and adverse environmental conditions.

Keywords: slum settlement, slum level, parameter overlay 


\section{PENDAHULUAN}

Wilayah pesisir adalah suatu wilayah peralihan (interface area) antara ekosistem daratan dan laut. Definisi dan batas wilayah pesisir yang digunakan di Indonesia adalah wilayah dimana daratan berbatasan dengan laut. Batas ke arah darat meliputi (1) secara ekologis: kawasan daratan yang masih dipengaruhi oleh proses-proses kelautan seperti pasang-surut, angin laut, dan intrusi air laut; (2) secara administrasi: batas terluar sebelah hulu dari desa pantai atau jarak definitif secara arbiter $2 \mathrm{~km}$ dari garis pantai. Sedangkan batas ke arah laut meliputi (1) secara ekologis: kawasan laut yang masih dipengaruhi oleh prosesproses alami di daratan seperti sedimentasi, dan mengalirnya air tawar kelaut, serta daerah-daerah laut yang dipengaruhi oleh kegiatan- kegiatan manusia di daratan; (2) secara administrasi: batas 4 mil dari garis pantai ke arah laut (Mahfud Effendy, 2009).

Pemanfaatan data penginderaan jauh dan SIG telah banyak dilakukan dalam kaitannya dengan wilayah pesisir dan lautan khususnya sektor perikanan dan pengelolaan wilayah pesisir dan lautan, seperti: aplikasi penginderaan jauh untuk memberikan informasi Zona Potensi Penangkapan Ikan (ZPPI), kesesuaian lahan perairan untuk usaha budidaya laut dan pariwisata bahari, identifikasi potensi wilayah pesisir (seperti hutan bakau, terumbu karang, padang lamun dan pasir), zonasi kawasankonservasi laut, analisa potensi ekonomi wilayah pesisir pulaupulau kecil, pengamatan perubahan garis pantai, analisa pencemaran lingkungan perairan dan lain sebagainya (Achmad Fachruddin Syah, 2010).

Kawasan Kumuh adalah sebuah kawasan dengan tingkat kepadatan populasi tinggi di sebuah kota yang umumnya dihuni oleh masyarakat miskin. Kawasan kumuh dapat ditemui di berbagai kota besar di Indonesia. Kawasan kumuh umumnya dihubunghubungkan dengan tingkat kemiskinan dan pengangguran tinggi. Kawasan kumuh dapat pula menjadi sumber masalah sosial seperti kejahatan, obatobat terlarang dan minuman keras. Di berbagai wilayah, kawasan kumuh juga menjadi pusat masalah kesehatan karena kondisinya yang tidak higienis (Asep Hariyanto, 2000). Permasalahan permukiman kumuh merupakan suatu permasalahan penanganan permukiman yang erat kaitannya dengan sisi pengadaan perumahan untuk masyarakat ekonomi lemah yang selalu timbul dalam kota-kota yang berkembang (Heryati, 2008).

Penilaian terhadap kondisi kekumuhan dilakukan secara menyeluruh di wilayah studi. Besarnya kesempatan setiap sampel untuk diteliti adalah sama, dengan pertimbangan keseragaman karakter populasi. Teknik yang digunakan untuk mendapatkan sampel dengan kesempatan yang sama dan keseragaman karakter di wilayah studi adalah sampel acakan (Random Sampling). Responden ditentukan berdasarkan sampel/sampling yang dihitung dengan rumus Slovin:

$$
\mathrm{n}=\frac{\mathrm{N}}{1+\mathrm{N}\left(\mathrm{e}^{2}\right)}
$$

Ket: $\quad \mathrm{n}=$ Jumlah Sampel (KK)

$\mathrm{N}=$ Total Populasi

$\mathrm{e}=$ Nilai Kritis $(0,1)$

(Evans Oktaviansyah, 2012).

Berikut merupakan perhitungan sampel dengan rumus slovin di kawasan pesisir Kecamatan Abeli:

Jumlah sampel di wilayah studi yang digunakan dalam penelitian dengan jumalah kepala keluarga yaitu $521(\mathrm{~N})$, berdasarkan perhitungan rumus tersebut sebagai berikut:

$$
\begin{aligned}
& \mathrm{n}=\frac{521}{1+521\left(0,1^{2}\right)} \\
& \mathrm{n}=\frac{521}{522\left(0,1^{2}\right)} \\
& \mathrm{n}=\frac{521}{5}
\end{aligned}
$$




$$
\mathrm{n}=\frac{\begin{array}{c}
522(0,01) \\
\end{array} \mathrm{n}=\mathrm{521}}{\mathrm{n}=\mathrm{100}}
$$

Karakter yang juga berpengaruh dalam keadaan kumuh lingkungan permukiman adalah tentang karakteristik lingkungannya baik yang di dalam lingkungan permukiman itu sendiri maupun yang ada di sekitar kawasan yang terkait juga dengan kecenderungan penggunaan lahannya (Nuning Aprilia,2016).

\section{METODE PENELITIAN}

Lokasi penelitian ini dilakukan di Kecamatan Abeli, Kota Kendari Provinsi Sulawesi Tenggara. Kecamatan Abeli merupakan salah satu dari beberapa Kecamatan yang ada di Kota Kendari.

Gambaran umum lokasi penelitian dibuat dalam bentuk Peta Lokasi Penelitian Kecamatan Abeli, sebagaimana disajikan pada Gambar 3.

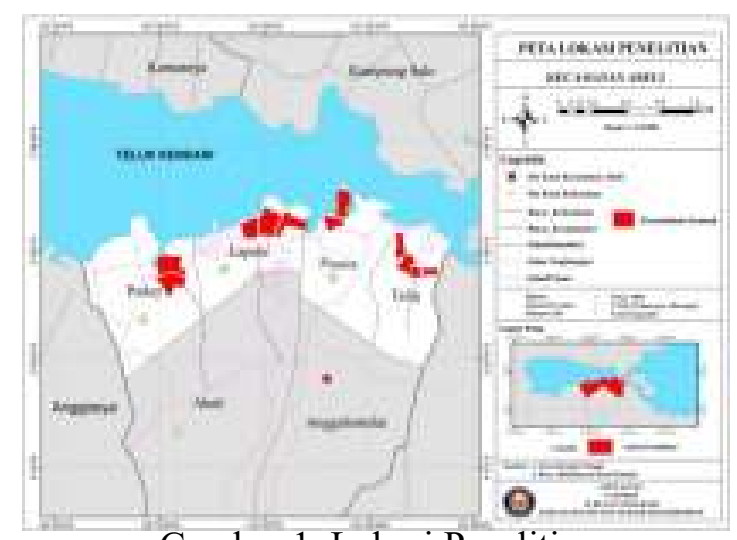

Gambar 1. Lokasi Penelitian

Jenis data yang digunakan dalam Data yang digunakan dalam penelitian ini adalah data primer dan data sekunder. Data primer adalah data yang diperoleh melalui pengumpulan data secara langsung di lapangan yaitu dengan cara melakukan observasi lapangan maupun di peroleh dengan memanfaatkan citra penginderaa jauh. Yang termasuk data primer dalam penelitian ini yaitu: Data hasil dari wawancara kemudian ditabulasi dan diberikan nilai pada masing-masing kriteria. Kemudian diolah menggunakan Arcgis dan untuk kondisi eksisting, melihat secara langsung kondisi eksisting yang ada di daerah penelitian berdasarkan hasil wawancara dengan warga setempat.

Sedangkan data sekunder yaitu data yang diperoleh dari instansi-instansi yang terkait dengan penelitian. seperti, data yang terkait tentang kependudukan.

Analisis data yang dilakukan dengan melakukan overlay pada semua parameter yang digunakan seperti peta kepadatan bangunan, kelayakan bangunan, aksesibilitas lingkungan, drainase lingkungan, pelayanan air bersih, pengelolaan air limbah, dan pengelolaan persampahan.

Dengan menggunakan bantuan perangkat lunak Sistem Informasi Geografis (SIG) ArcGIS 10.2 dapat dilakukan overlay dengan mudah. Software tambahan (intersect) Geoprocessing yang terintegrasi dalam Software ArcGIS 10.2 sangat berperan dalam proses ini. Di dalam Geoprocessing ini terdapat beberapa fasilitas overlay dan fasilitas lainnya seperti; union, merge, clip, intersect, dll. Dalam proses ini digunakan teknik overlay intersect. Cara dalam overlay intersect adalah pilih pada arctoolbox-analysis tool-overlay-intersect, kemudian akan muncul border intersect setelah itu masukan peta kepadatan bangunan, peta kelayakan bangunan, peta aksesibilitas lingkungan, peta drainase lingkungan, peta pelayana air bersih, peta pengelolaan air limbah, peta pengelolaan persampahan. kemudian input features. Simpan file pada output features class.

\section{HASIL DAN PEMBAHASAN}

\subsection{Kepadatan Bangunan}

Kepadatan bangunan setiap kawasan yang menjadi lokasi penelitian terdapat dua kelas yaitu kelas kepadatan sangat rendah dan kelas kepadatan rendah, dengan kelas kepadatan sangat rendah terdapat pada tiga kelurahan yaitu kelurahan Lapulu RT 03 dengan jumlah kepadatan 47 KK, kelurahan Poasia terdapat pada RT 03 dengan jumlah kepadatan $20 \mathrm{KK}$, RT 05 dengan jumlah 
kepadatan 34 KK. Kemudian kelurahan Talia terdapat tiga RT yaitu RT 01 dengan jumlah kepadatan $21 \mathrm{KK}$, RT 02 dengan jumlah $32 \mathrm{KK}$ dan RT 03 dengan jumlah kepadatan $39 \mathrm{KK}$.

Kepadatan bangunan dengan kelas kepadatan rendah terdapat pada tiga kelurahan yaitu kelurahan Pudai RT 01 dengan jumlah kepadatan $83 \mathrm{KK}$ dan RT 02 dengan jumlah kepadatan $58 \mathrm{KK}$. Kelurahan Lapulu yang terdapat pada RT 01 dengan jumlah kepadatan $57 \mathrm{KK}$ dan RT 02 dengan jumlah kepadatan $77 \mathrm{KK}$. Terakhir terdapat pada kelurahan Talia yaitu RT 4 dengan jumlah kepadatan 54 KK. Berdasarkan penjelasan tersebut kepadatan bangunan dapat dilihat berdasarkan jumalah kepala keluarga (KK) yang didapatkan dengan wawancara setiap kepala RT. Berikut merupakan peta kepadatan bangunan:

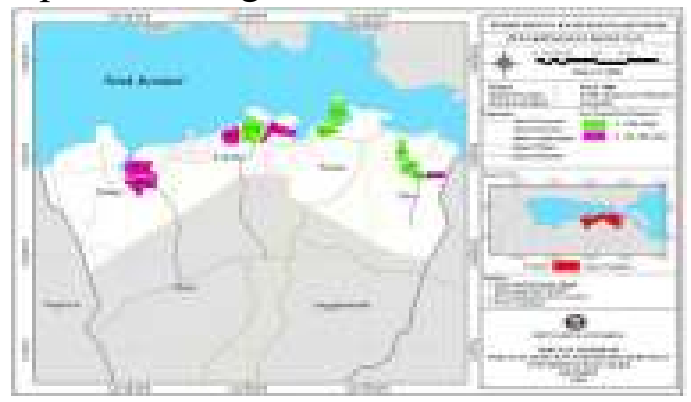

Sumber:Analisis Data Tahun 2018

Gambar 2. Peta Kepadatan Bangunan

\subsection{Kelayakan Bangunan}

Kelayakan bangunan hunian merupakan kelayakan bangunan dengan ciri rumah tidak memenuhi luas lantai perkapita $\geq 7,2 \mathrm{~m}^{2}$ yang telah ditetapkan oleh dirjen perumahan dan pemukiman.

Berdasarkan hasil analisis kelayak

an bangunan terdapat empat skor kelayakan yaitu skor 1 dengan nilai kelayakan $<10 \%$ terdapar di Kelurahan Poasia RT 03 dan 05, Kelurahan Talia RT 01 dan RT 04. Kemudian skor 2 dengan nilai $11-30 \%$ terdapat di Kelurahan Lapulu RT 01 dan 02 untuk skor 3 dengan nilai kelayakan bangunan $31-50 \%$ terdapat di Kelurahan Pudai RT 01 dan 02. Dan skor 5 dengan nilai $>70 \%$ terdapat di
Kelurahan Lapulu RT 03 dan Kelurahan Talia RT 02 dan 03. Berikut merupakan peta kelayakan bangunan:

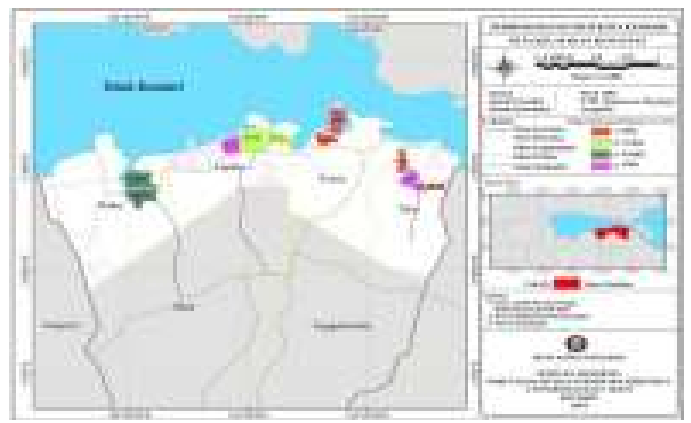

Sumber: Analisis Data Tahun 2018

Gambar 3. Peta Kelayakan Bangunan

\subsection{Drainase Lingkungan}

Drainase permukiman merupakan sarana atau prasarana dipermukiman untuk mengalirkan air hujan, dari suatu tempat ketempat lain. Karena peningkatan luas daerah yang ditutupi oleh perkerasan atau mengakibatkan waktu berkumpulnya air jauh lebih pendek, sehingga akumulasi air hujan yang terkumpul melampaui kapasitas drainase yang ada.

Berdasarkan hasil analisis drainase lingkungan terdapat tiga skor drainase yaitu skor $1<10 \%$ terdapat di Kelurahan Talia RT 01 dimana permukiman tidak terjadi genangan saat hujan. Untuk skor 2 terdapat di Kelurahan Pudai RT 01 Dan 02 dimana terjadi genangan sebesar 11$30 \%$. Dan untuk skor ke 5 dengan nilai $>70$ terdapat di Kelurahan Lapulu RT 01, 02 dan 03, Kelurahan Poasia RT 03 dan 05 dan Kelurahan Talia RT 02, 03, dan 04. Penyebab utama terjadinya genangan pada drainase yaitu adanya sampah plastik yang menyumbat atau berada dalam drainase sehingga pada saat hujan air tidak mengalir dengan baik. Berikut merupakan peta Drainase lingkungan:

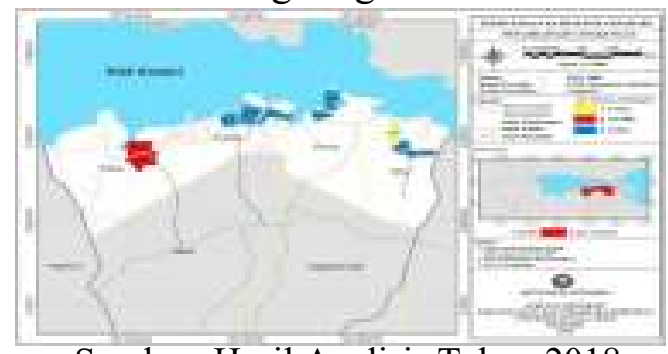

Sumber: Hasil Analisis Tahun 2018 Gambar 4. Peta Drainase lingkungan

Oktober--- 186 


\subsection{Aksesibilitas Lingkungan}

Aksesibilitas lingkungan dalam hal ini mengenai pelayanan jaringan jalan didalam lokasi kajian, bila ada bagian dalam lokasi yang tidak terlayani maka cakupan jaringan jalan belum memadai.

Berdasarkan hasil analisis aksesibi litas lingkungan dengan kondisi memadai diatas terdapat dua skor yaitu skor 1 dengan nilai aksesibilitas $<10 \%$ terdapat di Kelurahan Lapulu RT 03 , skor 5 dengan nilai aksesibilitas $>70 \%$ terdapat di Kelurahan Pudai RT 01 dan RT 02, Kelurahan Lapulu RT 02, Kelurahan Poasia RT 03 dan 05, kemudian Kelurahan Talia RT 01, 02, 03 dan 04. Kondisi ini di akibatkan tidak meratanya pembangunan jalan. Berikut merupakan peta aksesibilitas lingkungan:

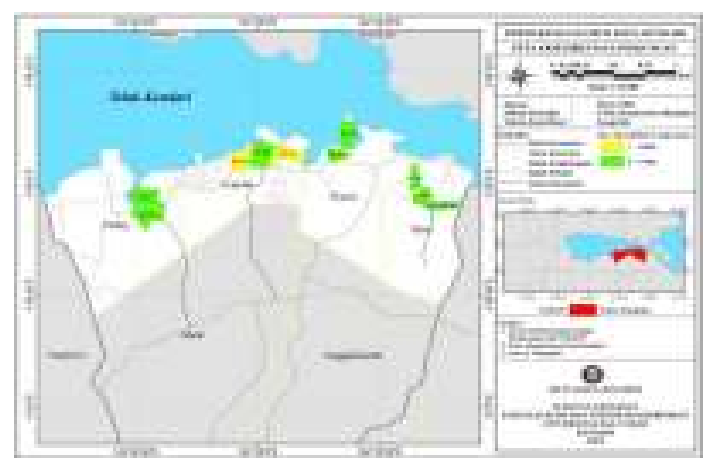

Sumber: Analisis Data Tahun 2018

Gambar 5. Peta Aksesibilitas Lingkungan

\subsection{Pelayanan Air Bersih}

Kewenangan masyarakat dalam menyelenggarakan pelayanan air bersih merupakan landasan atas kemampuan masyarakat untuk membantu kondisi mereka sendiri dalam memenuhi kebutuhan air bersih, artinya terjadi pengalihan tanggung jawab dalam pelayanan air bersih ini dari pemerintah kepada masyarakat.

Berdasarkan hasil analisis tersebut pelayanan bersih sudah terpenuhi setiap rumah tangga dengan memakai ledeng meteran/SR terdapat dua skor yaitu skor 2 dengan nilai $11-30 \%$ terdapat di
Kelurahan Pudai RT 01 dan Kelurahan Lapulu RT 01 dan RT 02. Untuk skor 5 dengan nilai pelayanan air bersih $>70 \%$ terdapat di Kelurahan Pudai RT 02, Kelurahan Lapulu RT 03, Kelurahan Poasia RT 03, dan 05, Kelurahan Talia RT 01, 02, 03 dan 04. Berikut merupakan peta pemenuhan pelayanan air bersih

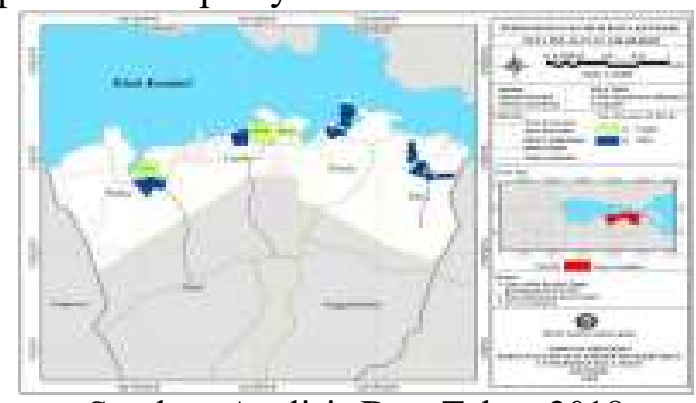

Sumber: Analisis Data Tahun 2018

Gambar 6. Peta Pelayanan Air Bersih

\subsection{Pengelolaan Air Limbah}

Pengolahan Air Limbah adalah sarana untuk mengolah limbah cair (limbah dari WC, air cuci/kamar mandi). Bagi masyarakat adalah IPAL untuk limbah WC lebih dikenal dengan sebutan septik tank. Pengelolaan air limbah ditentukan dengan melihat apakah sistem pengelolaan air limbah pada lokasi tidak memenuhi persyaratan yaitu kloset leher angsa terhubung dengan septik tank atau system pengelolahan komunal atau terpusat (septik tank/ MCK komunal). Pengelolaan sanitasi dapat dilihat dengan biasanya nggota rumah tangga buang air besar dimana seperti, jamban sendiri. Hal tersebut sudah terpenuhi untuk empat kelurahan dan sudah memiliki jamban sendiri. Berikut merupakan peta Pengelolaan air limbah/sanitasi:

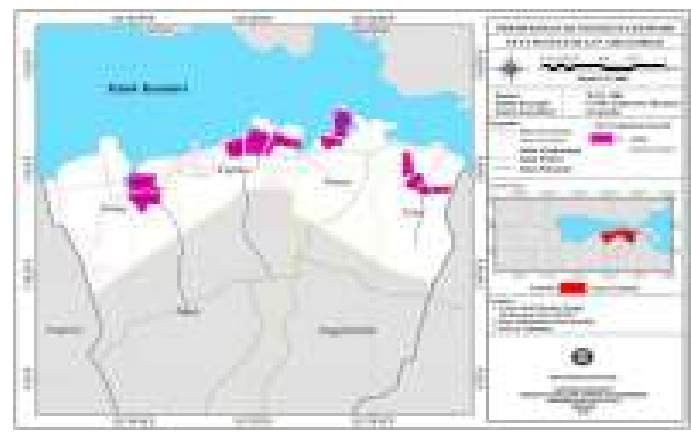

Sumber: Analisis Data Tahun 2018

Gambar 7. Peta Pengelolaan Air Limbah 


\subsection{Pengelolaan Persampahan}

Pengelolaan sampah adalah pengumpulan, pengangkutan, pemrosesan, daur ulang, atau pembuangan dari material sampah. Kalimat ini biasanya mengacu pada material sampah yang dihasilkan dari kegiatan manusia, dan biasanya dikelola untuk mengurangi dampaknya terhadap kesehatan, lingkungan, atau estetika. Pengelolaan sampah juga dilakukan untuk memulihkan sumber daya alam (resources recovery). Pengelolaan sampah bisa melibatkan zat padat, cair, gas, atau radioaktif dengan metode dan keterampilan khusus untuk masingmasing jenis zat.

Sistem persampahan pada lokasi tidak memnuhi ketentuan dengan melihat system pengangkutan sampah skala lingkungan (gerobak/ angkutan sampah) dengan frekuensi pengangkutan sampah dua kali seminggu.

Berdasarakan analisis hasil pengel olaan persampahan setiap kelurahan telah membuang sampah pada tempat pembuangan sampah sementara yang kemudian sampah tersebut diangkut oleh truk pengangkut sampah, Berdasarkan hasil wawancara dengan warga dilokasi tiap rumah dengan sampel yang telah ditentukan dalam membuang sampah setiap rumah ada lebih dari dua kali seminggu dan ada satu kali seminggu ke tempat pembuangan sampah sementara. Berikut merupakan peta pengelolaan persampahan:

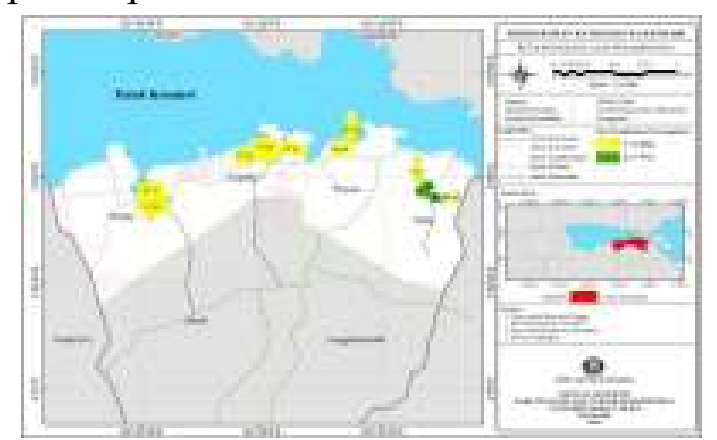

Sumber: Analisis Data Tahun 2018

Gambar 8. Peta Pengelolaan Persampahan
Tingkat kekumuhan permukiman psisir diperoleh dari hasil penelitian terhadap tujuh indikator yaitu kepadatan bangunan, kelayakan bangunan, kondisi jalan, kondisi drainase lingkungan, pelayanan air bersih, pengelolaan air limbah dan kondisi persampahan dari tujuh ketetapan yang di tetapkan oleh Dirjen Perumahan dan Permukiman, yang diperoleh dengan cara melakukan observasi lapangan atau survei lapangan. Kemudian data- data yang telah didapatkan dihitung dengan menggunakan rumus yang telah di tetapakan, dimana nilai dari masing-masing indikator dikalikan dengan persen untuk masingmasing indikator. Dari hasil tersebut maka akan diperoleh nilai yang telah ditetapkan sebelumnya, sehingga dapat menunjukan tingkat kekumuhan suatu kawasan.

Berdasarkan uraian diatas maka permukiman kumuh dalam penelitian ini diklasifikasikan dalam lima kelas yaitu sangat kumuh, kumuh berat, kumuh sedang, kumuh ringan dan tidak kumuh. Namun dari lima kelas yang di rencanakan tersebut hanya terdapat dua kelas yang menjadi hasil akhir dari penelitian yaitu kumuh sedang dan kumuh berat.

Untuk menghitung nilai tingkat kekumuhan digunakan rumus berikut (Dirjen Perumahan dan Pemukiman 2002):

$$
T K=\Sigma(n k x \text { bobot })
$$

\section{Keterangan:}

TK = Tingkat Kekumuhan

nk = Nilai kekumuhan, diperoleh dari nilai masing- masing indikator

bobot $=$ Persen unutk masing-masing indikator yang telah ditetapkan

Tabel 5. Nilai/indeks kekumuhan (Nilai TK adalah $1 \leq \mathrm{x}<5$ )

$\frac{\frac{\text { Indeks }}{1,0-1,4}}{\frac{\text { Tidak Kumuh }}{2,5-2,4}} \frac{\text { Kumuh Ringan }}{\text { Kumuh Sedang }}$




\section{$\underline{3,5-4,4} \quad$ Kumuh Berat 4,5 - 5,0 Sangat Kumuh}

Sumber: Dirjen Perumahan dan Permukiman

Kelas tingkat kekumuhan berdasarkan ke kedua klasifikasi tersebut ditunjukan pada tabel berikut:

Tabel 1. Klasifikasi Tingkat Kekumuhan

\begin{tabular}{|c|c|c|c|c|c|}
\hline No & Kelurahan & RT & \begin{tabular}{c|} 
Tingkat \\
Kekumahan \\
\end{tabular} & $\begin{array}{c}\text { Indeks } \\
\text { Kekumuhan } \\
\end{array}$ & $\begin{array}{l}\text { Luas } \\
(\mathrm{km} 2) \\
\end{array}$ \\
\hline \multirow[t]{2}{*}{1} & Pudai & 01 & Kumuh Berat & $3,5-4,4$ & 2.948 \\
\hline & & 02 & Kumuh Sedang & $2,5-3,4$ & 2.765 \\
\hline \multirow[t]{3}{*}{2} & Lapulu & 01 & Kumuh Sedang & $2,5-3,4$ & 2.255 \\
\hline & & 02 & "Kumuh Sedang & $2,5-3,4$ & 1.896 \\
\hline & & 03 & Kumuh Berat & $3,5-4,4$ & 3.184 \\
\hline \multirow[t]{2}{*}{3} & Poasia & 03 & Kumuh Sedang & $2,5-3,4$ & 2.303 \\
\hline & & 05 & Kumuh Sedang & $2,5-3,4$ & 1.329 \\
\hline \multirow[t]{4}{*}{4} & Talia & 01 & Kumuh Sedang & $2,5-3,4$ & 1.297 \\
\hline & & 02 & Kumuh berat & $3,5-4,4$ & 1.341 \\
\hline & & 03 & Kumuh berat & $3,5-4,4$ & 0.630 \\
\hline & & 04 & Kumuh berat & $3,5-4,4$ & 0.649 \\
\hline
\end{tabular}

Sumber: Hasil Analisi Data Tahun 2018

Berikut Merpakan peta indeks kekumuhan permukiman pesisir di Kecamatan Abeli:

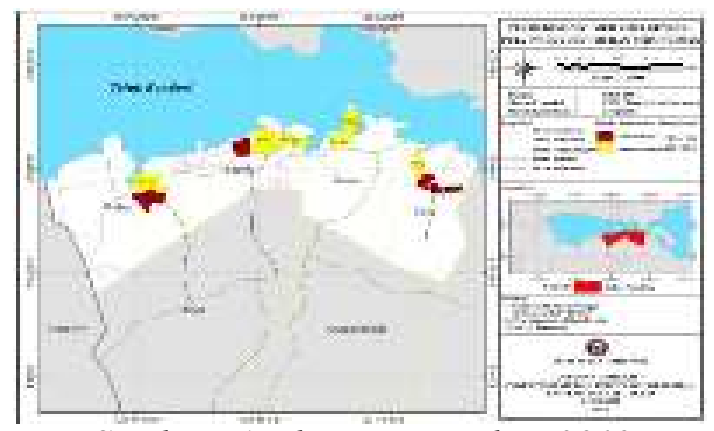

Sumber: Analisis Data Tahun 2018

Gambar 9. Peta Indeks Kekuhan Permukiman

Berdasarakan hasil analisis kekumuhan permukiman diperoleh luas untuk tingkat kekumuhan sedang dan berat dapat dilihat pada tabel sebagai berikut:

Tabel 22. Luas Indeks Kekumuhan Permukiman

\begin{tabular}{|lr|r|r|r}
\hline No & Keterangan & \multicolumn{1}{c}{ Luas (Ha) } & \multicolumn{2}{c}{ Persen (\%) } \\
\hline \hline 1 & Kumuh Sedang & 13.502 & 65 & \\
\hline 2 & Kumuh Berat & 7.283 & 35 \\
\hline \multicolumn{3}{c}{ Jumlah Total Luas } & 20.786 & 100 \\
\hline
\end{tabular}

Sumber: Hasil Analisis Data Tahun 2018

Berdasarkan hasil analisis diatas terdapat dua kelas indeks kumuh permukiman pesisir di Kecamatan Abeli yaitu sebagai berikut:

\section{Permukiman Kumuh Sedang}

Permukiman kumuh dengan kelas sedang berada pada empat Kelurahan yang masing-masing kawasan memiliki luasan kumuh yang berbeda-beda yaitu Kelurahan Pudai, Lapulu, Poasia dan Talia. Dimana Kelurahan Pudai terdapat pada RT 02 dengan luas $2.948 \mathrm{~km}^{2}$. Kelurahan Lapulu terdapat pada RT 01 denan luas $2.255 \mathrm{~km}^{2}$ dan RT 02 dengan luas, $1.896 \mathrm{~km}^{2}$. Kelurahan Poasia RT 03 denan luas $2.303 \mathrm{~km}^{2}$ dan 05 dengan luas 1,329, Kelurahan Talia RT 01 dengan luas 1.297.

Kondisi pemenuhan sarana dan prasarana di permukiman ini ada yang cukup baik namun ada juga yang kurang baik. Permukiman pada kelas 2 ini memiliki kondisi kepadatan bangunan sangat rendah yaitu 20-47 unit/ha, dengan kondisi jalan yang cenderung memadai. Permukiman yang memiliki saluran drainase yang baik dikarenakan saat hujan tidak tergenang. Kondisi persampahan yang mulai baik dalam pengolahannya yaitu dengan membuang sampah pada tempat pembuangan sampah semntara atau tempat pembuangan sampah akhir dan kondisi lingkungan yang cukup baik.

\section{Permukiman Kumuh Berat}

Permukiman kumuh dengan kelas berat berada pada tiga kelurahan dengan luas kawasan yang berbeda-beda yaitu kelurahan Pudai, kelurahan Lapulu dan kelurahan Talia. Kelurahan Pudai terdapat pada RT 01 dengan luas $2.948 \mathrm{~km}^{2}$. Kelurahan Lapulu terdapat pada, RT 03 dengan luas 3.184 ha. Kelurahan Talia terdapat pada RT 02 dengan luas 1.341 ha, RT 03 dengan luas 0.630 ha dan RT 04 $0.649 \mathrm{~km}^{2}$.

Kawasan kumuh di kelurahan Pudai, Lapulu dan Talia memiliki kepadatan bangunan rendah, begitu pula dengan kelas permukiman kumuh berat ini kepadatan penduduknya yaitu 57-83 unit/ha. Memilki kondisi lingkungan yang buruk, ditandai dengan tidak maksimalnya fungsi saluran drainase sehingga mengakibatkan saluran menguap akibat pendangkalan dan tersumbatnya akibat sampah yang ada pada saluran drainase 
Masih banyak terdapat gundukan sampah di lingkungan rumah. Kebutuhan jalan yang belum memadia dan ketidak efisiennya jadwal pengangkutan sampah yang terjadwal seminggu sekali namun terkadang tidak terlaksana.

Berdasarkan hasil survey lapangan menunjukan bahwa parameter atau kriteria yang ditetapkan oleh Dirjen Perumahan dan Permukiman tidak dapat digunakan pada semua lokasi permukiman kumuh karena setiap daerah memilki kondisi karkteristik wilayah yang berbeda- beda. Kemudian untuk dapat melihat secara mendalam bahwa permukiman kumuh tidak hanya dilihat dari aspek lingkungan fiik saja melainkan juga dari aspek ekonomi, karena setiap individu tidak menginginkan rumah dan kehidupan yang tidak sejahtera, maka dari itu aspek ekonomi juga sangat penting dalam menciptakan permukiman kumuh, kemudia aspek budaya juga sangat mempengaruhi karena dilihat dari budaya permukiman pesisir yang banyak dihuni oleh masyarakat nelayan menyebabkan bentuk bangunan rumah cenderung panggung dan kayu.

\section{Kesimpulan}

Berdasarkan hasil analisis dapat disimpulkan sebagai berikut:

Kawsasan peisisir Kecamatan Abeli terdiri dari empat Kelurahan yaitu Kelurahan Puday, Lapulu, Poasia dan Talia. Dengan kondisi eksisting untuk tingkat permukiman kumuh sedang memiliki kondisi lingkungannya umumnya cenderung menengah, dimana terdapat beberapa aspek yang memiliki kesamaan dengan permukiman kumuh ringan. Sedangkan kondisi kumuh berat kondidsi lingkungannya buruk, terdapat kecenderungan bahwa semakin buruk tingkat kekumuhan permukiman, maka semakin buruk pula kondisinya dengan memilki kondisi sarana dan prasarana yang tidak memadai dan kondisi lingkungan yang sangan buruk.

Permukiman kumuh di Kecamatan

Abeli kawasan pesisir terdiri dari dua kelas yaitu kumuh sedang dan kumuh berat. Kumuh sedang dengan indeks 2,5-
3,4 terdapat pada Kelurahan Pudai, Lapulu, Poasia dan Talia. Kelurahan Pudai terdapat di RT 02 dengan luas 2.765 km2, Kelurahan Lapulu RT 01 dengan luas 2.255 dan 02 dengan luas 1.896 . Kelurahan Poasia terdapat pada RT 03 dengan luas 2.303 ha dan RT 05 dengan luas $1.329 \mathrm{~km}^{2}$ dan Kelurahan Talia pada RT 01 dengan luas $1.297 \mathrm{~km}^{2}$. Kelas kumuh berat dengan indeks 3,5- 4,4 terdiri dari Kelurahan Pudai RT 01 dengan luas $2.948 \mathrm{~km}^{2}$. Kelurahan Lapulu RT 03 dengan luas $3.184 \mathrm{~km} 2$. Kelurahan Talia RT 02 dengan luas $1.341 \mathrm{~km}^{2}$, RT03 dengan luas $0.630 \mathrm{~km}^{2}$ dan RT 04 dengan luas $0.649 \mathrm{~km}^{2}$.

\section{DAFTAR PUSTAKA.}

Aprilia, N, 2016. Pemetaan Kawasan Permukiman Kumuh di Kecamatan Kendari Barat Kota Kendari. Kendari.

Effendy, M, 2009. Pengelolaan Wilayah Pesisir Secara Terpadu: Solusi Pemanfaatan Ruang, Pemanfaatan Sumberdaya Dan Pemanfaatan Kapasitas Asimilasi Wilayah Pesisir Yang Optimal Dan Berkelanjutan.

Evans, O, 2012. Penataan Permukiman Kumuh Rawan Rencana Kebakaran di Kelurahan Lintas Ujung Kota Tarakan. Universitas Brawijaya.

Fachruddin, S, A, 2010. Penginderaan Jauh Dan Aplikasinya Di Wilayah Pesisir Dan Lautan

Hariyanto A, 2000. Strategi Penanganan Kawasan Kumuh Sebagai Upaya Menciptakan Lingkungan Perumah an Dan Permukiman Yang Sehat (Contoh Kasus : Kota Pangkalpinang. Bandung).

Heryati, 2008. Penanganan Kawasan Permukiman Kumuh Di Kelurahan Limba B Melalui Peremajaan (Renewal). 